\title{
The pathology of meconium ileus equivalent
}

\author{
I JEFFREY,${ }^{*}$ D DURRANS, $\dagger$ M WELLS, $\ddagger$ H FOX*
}

From the Departments of *Pathology and $†$ Surgery, University of Manchester, and the Department of $\ddagger$ Pathology, University of Leeds

SUMMARY A case of meconium ileus equivalent in a 25-year-old woman with cystic fibrosis is reported and the pathology of this condition is described. On gross examination the lumen of the terminal ileum was completely obstructed by a mass of inspissated faecal material with a puttylike consistency. The principal microscopic findings were plugging of the mucosal crypts with mucoid secretion, distention of goblet cells and the presence of a thick layer of mucus, admixed with faecal material, adherent to the mucosal surface. Mucin histochemistry demonstrated sulphomucin in the terminal ileum, although acidic mucins in the normal small intestine are almost exclusively non-sulphated.

Approximately $15 \%$ of patients with fibrocystic disease of the pancreas present in the first few days of life with meconium ileus. ${ }^{1}$ Intestinal obstruction due to mechanical blockage of the bowel lumen with abnormal, inspissated faecal material can, however, also occur in these patients outside the neonatal period, an entity known as meconium ileus equivalent. ${ }^{2}$ This latter complication may develop at any age but is commonest in adolescents and adults. ${ }^{3}$ Recent reviews from large cystic fibrosis (CF) clinics in the USA estimate that up to $20 \%$ of sufferers over the age of $12 \mathrm{yr}$ may be affected at some stage $^{34}$ The greatly improved life expectancy of patients with $\mathrm{CF}$ over the past two decades ${ }^{5}$ means that this type of intestinal obstruction is being seen with increasing frequency, often away from specialist paediatric hospitals. If meconium ileus equivalent is diagnosed clinically, it can usually be treated medically. ${ }^{6}$ Thus many pathologists in the UK are not familiar with the surgical pathology of this condition, details of which in standard British textbooks are extremely scanty. ${ }^{7}$ We present a case of meconium ileus equivalent showing the characteristic pathological changes.

\section{Case report}

A 25-year-old woman presented with a forty hour history of colicky lower abdominal pain associated with copious vomiting. The pain was localised, nonradiating with no precipitating or relieving factors. She had been diagnosed as suffering from CF in

Accepted for publication 29 June 1983 childhood, and had secondary bronchiectasis and steatorrhoea. An oral contraceptive was her only medication, although Pancrex V had been taken up until two months before admission.

On examination the patient appeared toxic; she was pyrexial, temperature $37 \cdot 8^{\circ} \mathrm{C}$, with a pulse rate of $104 / \mathrm{min}$. The abdomen was distended and tympanic and palpation elicited great discomfort in the right iliac fossa, with local guarding and rebound tenderness. Bowel sounds were present and normal in character. The white blood cell count was raised at $15.9 \times 10^{9} / 1$, but other investigations were unremarkable.

A clinical diagnosis of acute appendicitis was made and the patient submitted to laparotomy. At operation the appendix looked normal but the distal $40 \mathrm{~cm}$ of the terminal ileum were congested and appeared inflamed. The mesentery of the small bowel was thickened and the mesenteric lymph nodes were markedly enlarged. The large intestine was apparently normal. A diagnosis of acute Crohn's disease was made and the terminal ileum and proximal part of the ascending colon was resected. Postoperatively the patient developed a chest infection, but recovery was otherwise uneventful.

\section{Material and methods}

Multiple blocks were taken at $3 \mathrm{~cm}$ intervals along the length of the specimen, and sections stained with haematoxylin and eosin. Selected sections were also stained with periodic acid-Schiff (PAS), diastase periodic acid-Schiff (D-PAS), alcian blue (AB) $\mathrm{pH} 2 \cdot 5 / \mathrm{PAS}$, high iron diamine (HID)/AB 
Table 1 Special mucin stains and their interpretation

\begin{tabular}{|c|c|c|}
\hline Method & Interpretat & tion \\
\hline $\begin{array}{l}\text { Diastase-periodic acid Schiff } \\
\text { (D-PAS) }\end{array}$ & $\begin{array}{l}\text { Magenta } \\
\text { Negative }\end{array}$ & $\begin{array}{l}\text { Neutral mucins } \\
\text { Some sialomucins } \\
\text { Sulphomucins } \\
\text { o-acetyl sialomucins }\end{array}$ \\
\hline $\begin{array}{l}\text { Periodate-borohydride } \\
\text { KOH/PAS }^{9}\end{array}$ & $\begin{array}{l}\text { Magenta } \\
\text { Negative }\end{array}$ & $\begin{array}{l}o \text {-acetyl sialomucins } \\
\text { All other mucins }\end{array}$ \\
\hline Alcian blue $(\mathrm{AB}) \mathrm{pH} 2 \cdot 5 / \mathrm{PAS}^{10}$ & $\begin{array}{l}\text { Blue } \\
\text { Purple } \\
\text { Magenta }\end{array}$ & $\begin{array}{l}\text { Sulphomucins } \\
o \text {-acetyl sialomucins } \\
\text { PAS positive acid } \\
\text { mucins or mixtures of } \\
\text { neutral and acid } \\
\text { mucins } \\
\text { Neutral mucins }\end{array}$ \\
\hline $\begin{array}{l}\text { High iron diamine (HID)/ } \\
\mathrm{AB} \text { pH } 2 \cdot 5^{\prime 1}\end{array}$ & $\begin{array}{l}\text { Brown } \\
\text { Blue }\end{array}$ & $\begin{array}{l}\text { Sulphomucins } \\
\text { Sialomucins }\end{array}$ \\
\hline
\end{tabular}

and periodate borohydride (PB)/KOH/PAS (see Table 1). In addition a series of slides were stained with Sudan black, Masson fontana, Ziehl-Neelsen, Perls' and Schmorl's ferriferrocyanide. Three cleared, unstained sections from different parts of the specimen were mounted in Xam and examined under ultraviolet light produced by a Leitz Wetzlar microscope equipped with an MBO/200 Watt lamp, a BG12 exciter filter and a $\mathrm{K} 530 \mathrm{~nm}$ barrier filter.

\section{PATHOLOGY}

\section{Naked eye appearance}

The specimen comprised $42 \mathrm{~cm}$ of terminal ileum together with the caecum and proximal $7 \mathrm{~cm}$ of ascending colon. The appendix was received separately. The lumen of the terminal ileum was obstructed by a large mass of light brown material with a putty-like consistency, which was difficult to dislodge from the underlying mucosa. The mucosal folds of both the large and small intestine were coarse and prominent with an adherent layer of

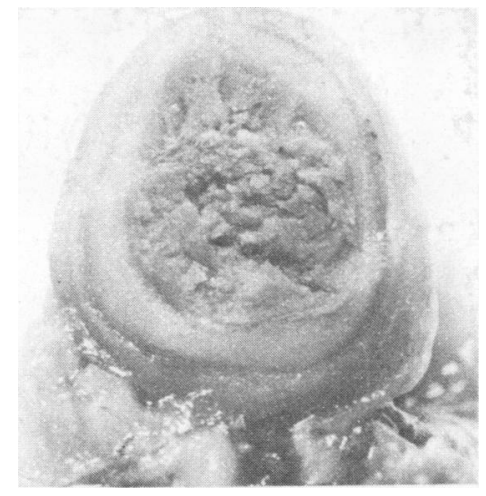

Fig. 2 Macroscopic appearance of a transverse section through the appendix. The lumen is dilated and occluded by inspissated faecal material. $\times 3.5$

pale, granular material (Fig. 1). No ulceration was evident. The muscle of the bowel wall was slightly thickened and showed a distinctive tan discolouration. The serosa was markedly congested but its surface was smooth with no obvious fibrinous exudate.

The appendix measured $10 \mathrm{~cm}$ in length and had a maximum diameter of $1 \cdot 1 \mathrm{~cm}$. The serosal vessels were injected but there was no evidence of pus formation or perforation. The lumen was significantly dilated and filled with firm, pale inspissated faeces (Fig. 2).

\section{MICROSCOPIC FEATURES}

Sections from both the terminal ileum and the colon showed a striking picture. The mucosal crypts were dilated and plugged with abundant mucoid secretion which in places had a laminated appearance (Fig. 3). There was a thick layer of mucus, admixed with faecal material, overlying the surface of the superficial epithelium. This was particularly marked in the small intestine at the base of the mucosal folds,

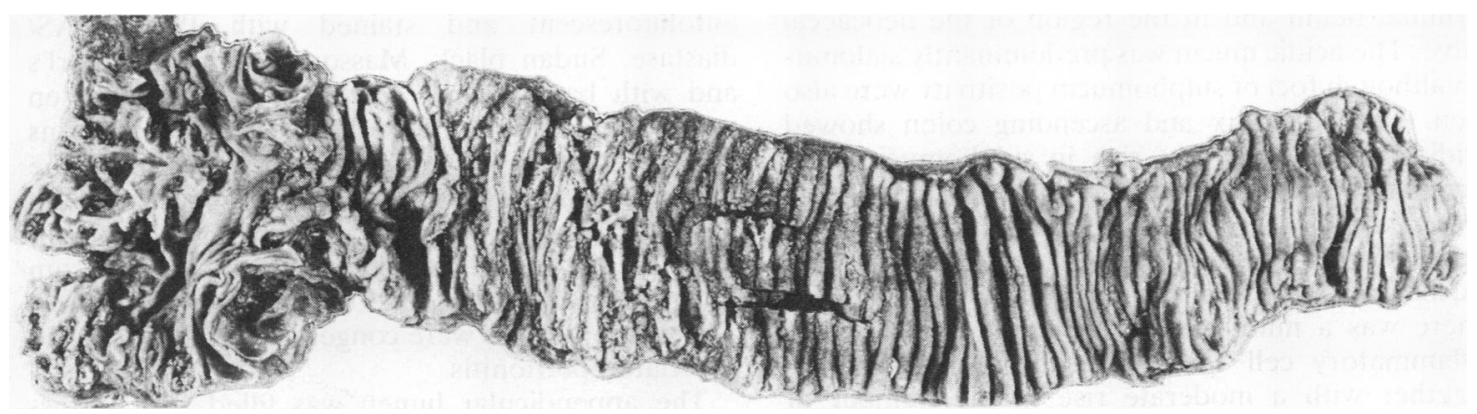

Fig. 1 Operative specimen comprising terminal ileum, caecum and proximal ascending colon. The obstructing plug of faecal material has been removed. The mucosal folds are prominent and bear an adherent layer of pale, granular material. $\times 1 / 3$ 


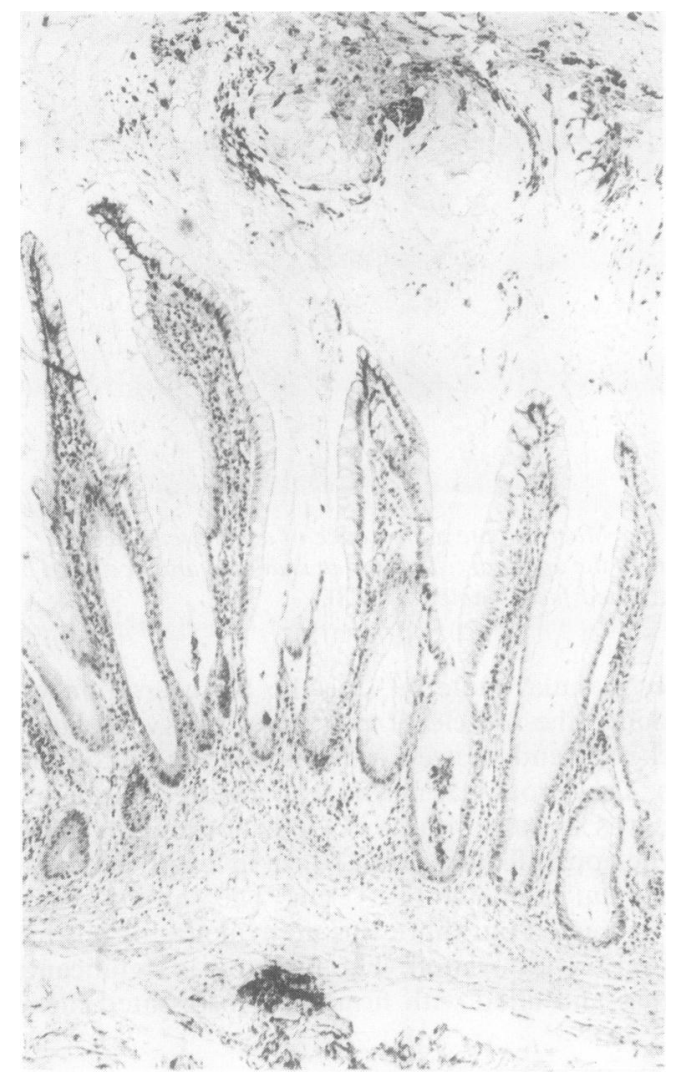

Fig. 3 Terminal ileum showing mucoid plugging of the crypts and a thick layer of mucus admixed with faecal material adherent to the mucosal surface. Haematoxylin and eosin $\times 50$

resulting in compression and distortion of the villi (Fig. 4). Many of the goblet cells were enlarged and distended. Mucin histochemistry revealed greatly increased amounts of extracellular mucus. A combination of acid and neutral mucin was seen in the terminal ileum and in the region of the ileocaecal valve. The acidic mucin was predominantly sialomucin although foci of sulphomucin positivity were also seen. The appendix and ascending colon showed acidic mucin which was rich in sulphomucin. The terminal ileum, appendix and colon all showed the presence of $o$-acetylated sialomucin (Table 2).

In addition to the glandular abnormalities, the mucosa also showed focal lymphoid hyperplasia. There was a mild, diffuse increase in the chronic inflammatory cell content of the lamina propria together with a moderate rise in the number of eosinophils. No crypt abscesses or granulomata were noted and there was no ulceration. Parasites were not identified in any area. These mucosal changes,

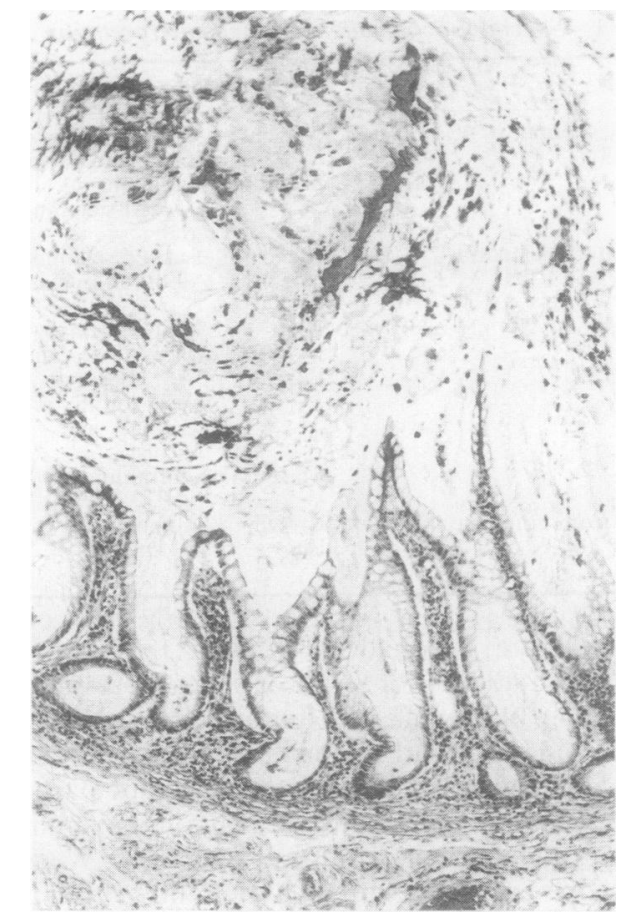

Fig. 4 At the base of the mucosal folds in the terminal ileum the large quantities of extracellular mucin have caused compression and distortion of the villi. Haematoxylin and eosin $\times 50$

although present throughout the specimen, were rather patchy in the colon and in the proximal part of the ileum.

The submucosa was congested and oedematous but showed no other abnormality. In sections stained with haematoxylin, fine granules of yellowbrown pigment were seen within smooth muscle cells in the muscularis propria. Special stains showed that these were composed of lipofuscin; they were autofluorescent and stained with PAS, PAS/ diastase, Sudan black, Masson fontana, Schmorl's and with basic fuchsin in the long Ziehl-Neelsen technique, but not with Perls' (Fig. 5). These stains also revealed a few granules of lipofuscin in the muscularis mucosae which were not apparent in the haematoxylin and eosin preparations. No lipofuscin was noted in the walls of blood vessels. Apart from the presence of pigment, the muscle was normal. The serosal vessels were congested but there was no associated peritonitis.

The appendicular lumen was filled with inspissated mucus and faeces, similar to that noted in the main specimen. The mucosal lining was largely flattened and the crypts compressed, but in places 
Table 2 Results

\begin{tabular}{|c|c|c|c|c|c|c|c|c|c|c|c|c|c|c|}
\hline & \multicolumn{2}{|c|}{$D-P A S$} & \multicolumn{6}{|c|}{$A B / P A S$} & \multicolumn{4}{|c|}{$H I D / P A S$} & \multirow{2}{*}{\multicolumn{2}{|c|}{$\underset{P A S}{P B / K O H /}$}} \\
\hline & \multirow[b]{2}{*}{$I$} & \multirow[b]{2}{*}{$E$} & \multicolumn{2}{|l|}{ Blue } & \multicolumn{2}{|c|}{ Purple } & \multicolumn{2}{|c|}{ Magenta } & \multicolumn{2}{|l|}{ Brown } & \multicolumn{2}{|l|}{ Blue } & & \\
\hline & & & $I$ & $E$ & $I$ & $E$ & $I$ & $E$ & $I$ & $E$ & $I$ & $E$ & $I$ & $E$ \\
\hline Appendix & + & +++ & +++ & +++ & - & + & ++ & ++ & +++ & ++ & + & ++ & +++ & + \\
\hline Ascending colon & + & ++ & +++ & +++ & - & + & - & - & +++ & ++ & + & + & +++ & + \\
\hline Ileocaecal valve & ++ & +++ & ++ & ++ & + & ++ & + & + & + & + & ++ & +++ & + & + \\
\hline Terminal ileum & +++ & +++ & ++ & ++ & ++ & ++ & - & ++ & + & + & +++ & +++ & + & + \\
\hline
\end{tabular}

$\mathrm{I}=$ intracellular: $\mathrm{E}=$ extracellular.

glandular dilation and plugging with mucoid secretion was present (Fig. 6). The smooth muscle of the appendix also contained lipofuscin. There was no associated inflammation.

The mesenteric lymph nodes showed marked reactive hyperplasia but no evidence of lymphadenitis.

\section{Discussion}

Fibrocystic disease of the pancreas (CF) is an auto-

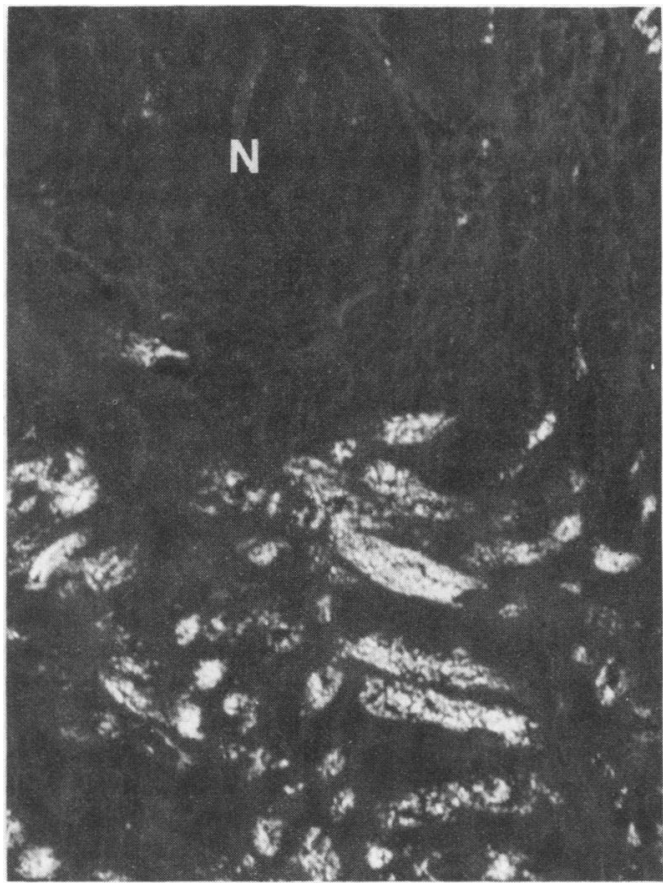

Fig. 5 Unstained section of ileum viewed under ultraviolet light. The lipofuscin granules within muscle fibres of the muscularis propria are brightly fuorescent. $N=$ nerve. $\times$ 350 somal recessive disorder characterised by widespread abnormalities in mucus cells and serous glands. The classical clinical features of chronic pulmonary disease, pancreatic insufficiency and abnormal electrolyte concentrations in sweat are found in most patients, but may be accompanied by a variety of signs and symptoms referable to other organs and tissues. ${ }^{3}{ }^{12}$ Indeed, the manifestations of the disease are protean and in some patients gastrointestinal problems other than malabsorption dominate the clinical picture. ${ }^{2}$

The development of acute intestinal obstruction in post-neonatal CF patients as a result of faecal impaction, was first described by Rasor and Stevenson in $1941 .{ }^{13}$ The phrase "meconium ileus equivalent" was coined by Jensen in 1962 to emphasise the similarity in pathogenesis between this condition and intestinal obstruction in newborn CF patients. ${ }^{14}$

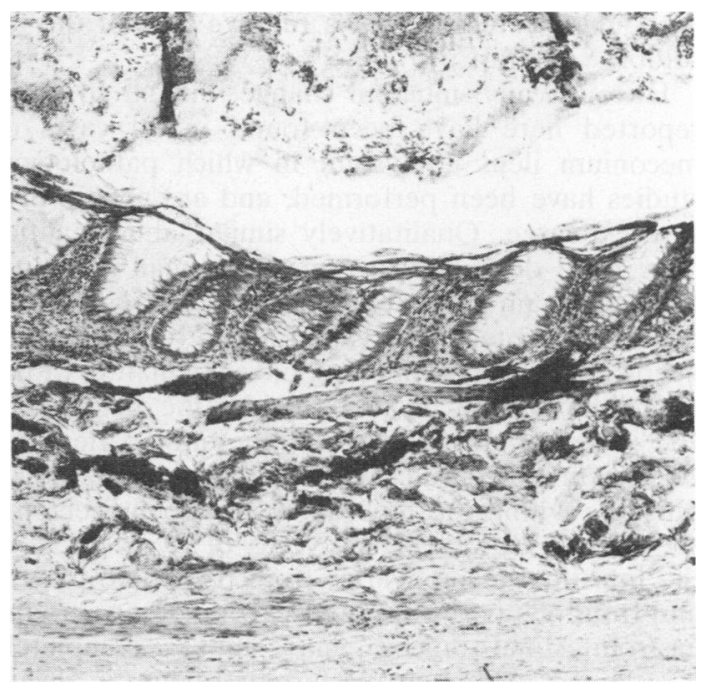

Fig. 6 The mucosal lining of the appendix is compressed and the crypts are plugged with mucoid material. Haematoxylin and eosin $\times 50$ 
At that time meconium ileus equivalent was considered to be rare, and in 1964 Snyder et al could only find 19 reported cases. ${ }^{15}$ However it is now realised that acute intestinal obstruction due to faecal impaction is far from uncommon in these patients. Abnormal accumulation of faecal material may also cause subacute obstruction, resulting in chronic abdominal pain, and in some CF patients asymptomatic faecal masses are detectable on plain abdominal $x$-ray or on abdominal palpation. ${ }^{316}$ Although originally reserved for episodes of acute obstruction, the term meconium ileus equivalent is now often applied to any form of faecal retention in CF patients after early infancy. ${ }^{16} 17$

The pathological changes illustrated here are characteristic of meconium ileus equivalent. The large mass of abnormal faecal material causing obstruction may be confined to the terminal ileum or may extend into the caecum and ascending colon. On occasions it may be so firmly adherent to the inner surface of the bowel wall that removal is only accomplished by stripping of the superficial epithelium..$^{18} 19$ The $\tan$ discolouration of the gastrointestinal smooth muscle is an interesting phenomenon. Although not often commented upon, in a necropsy study this abnormality was found consistently in all CF patients over the age of 5 years. ${ }^{20}$ Deposition of pigment was most marked in the oesophagus, ileum and appendix and the amount increased with age ${ }^{20}$ Lipofuscin accumulation in the muscle wall of the bowel has also been found sporadically in patients with malabsorption due to a variety of other causes, and is not specific to CF. ${ }^{7}$ It is thought to result from a relative lack of the fat soluble vitamin $\mathrm{E}^{20}$

Histologically, mucosal changes similar to those reported here have been found in all cases of meconium ileus equivalent in which pathological studies have been performed, and are always of a severe degree. Qualitatively similar abnormalities have been described in the upper small intestine, terminal ileum and colon of some CF patients who do not have intestinal obstruction. ${ }^{21-23}$ Indeed it has been suggested that microscopic examination of the rectal mucosa may be a useful aid in the diagnosis of CF. ${ }^{22}$ Furthermore, the possibility that a patient has CF may first be raised after the recognition of mucus plugging within the mucosa of an appendicectomy specimen. ${ }^{24}$ However the severity of involvement of the intestinal glands varies from patient to patient and from one part of the bowel to another, and the gastrointestinal mucosa may appear completely healthy. ${ }^{25}{ }^{26}$ Although the terminal ileum is always abnormal in meconium ileus equivalent, it is not clear whether the demonstration of changes in jejunal or rectal biopsies will identify patients at risk of developing this complication. It has been hinted that meconium ileus equivalent is more common in survivors of neonatal meconium ileus than in $\mathrm{CF}$ patients who present with respiratory problems. ${ }^{17}$

Pathological abnormalities in the gastrointestinal mucosa of CF patients are thought to result from the presence of abnormal quantities of mucin and there is increasing evidence that this build up is secondary to production of an abnormal glycoprotein. Wesley et al have reported that both the carbohydrate content and the density of intestinal mucin in CF patients are significantly greater than in controls. ${ }^{27}$ They suggest that $\mathrm{CF}$ mucins are more highly glycosylated and have a more highly branched oligosaccharide structure. Both these changes would tend to cause CF mucin to gel, thus hindering clearance and predisposing to mucus accumulation. In our patient, histological studies (apart from demonstrating an obvious quantitative increase in mucin) have revealed foci of intense positivity for sulphomucin in the terminal ileum. This is an interesting finding in view of the fact that several workers have shown that the acidic mucin component of the normal small intestine is almost exclusively nonsulphated..$^{28}$ This abnormality is, however, not limited to patients with meconium ileus equivalent; Morrissey and Tymvios have recently reported a quantitative increase in sulphomucins in the ileum of CF infants, none of whom showed evidence of intestinal obstruction. ${ }^{30}$

The pathogenesis of meconium ileus equivalent has not been fully elucidated, although the abnormally viscous intestinal mucus together with a lack of pancreatic enzymes are thought to be of importance in this regard. ${ }^{3}$ Although a decrease in pancreatic enzymes might be expected to increase intestinal hurry by causing steatorrhoea, breakdown of intestinal glycoprotein is impaired, and part of the treatment of meconium ileus equivalent involves the administration of appropriate pancreatic enzyme supplements. ${ }^{6}$

We would like to thank Mr Anscombe, under whose care the patient was admitted, for permission to publish the clinical details of this case. We are grateful to Mrs L Chawner and Mrs M Haigh for assistance with the special stains and fluorescence microscopy, to Mrs P Bellinger for typing the manuscript and to Mrs $J$ Crosby for preparing the photographs.

Dr Jeffrey is a Wellcome Trust Fellow in Pathology.

\footnotetext{
References

' Barbero GJ, Shwachman H, Grand R, Woodruff C. Gastrointestinal and nutritional manifestations of cystic
} 
fibrosis. In: Mangos JA, Talamon RL, eds. Cystic fibrosis Projections into the future. New York: Stratton Intercontinental Medical Book Corporation, 1976:83-111.

${ }^{2}$ Kopel FB. Gastrointestinal manifestations of cystic fibrosis. Gastroenterology 1972;62:483-91.

${ }^{3}$ Di Sant' Agnese PA, Davis PB. Cystic fibrosis in adults. 75 cases and a review of 232 cases in the literature. Am J Med 1979;66:121-32.

4 Shwachman H, Kowalski M, Khan K. Cystic fibrosis: a new outlook. 70 patients above 25 years of age. Medicine 1977;56:129-49.

${ }^{5}$ Roy CC. Gastrointestinal and hepatobiliary complications: changing pattern with age. In: Sturgess JM, ed. Perspectives in cystic fibrosis. Canadian Cystic Fibrosis Foundation, Canada. Proceedings of the 8th International Cystic Fibrosis Congress, 1980:190-7.

- Anderson CM, Goodchild MC. Meconium ileus equivalent. In: Cystic fibrosis. Manual of diagnosis and management. Oxford, London, Edinburgh, Melbourne: Blackwell Scientific Publications, 1976:97-99.

' Morson BC, Dawson IMP. Gastrointestinal pathology. Oxford, London, Edinburgh, Melbourne: Blackwell Scientific Publications, 1972.

- Symmers W St C, ed. Systemic Pathology Vol 3. Edinburgh, London, New York: Churchill Livingstone, 1978.

' Culling CFA, Reid PE, Clay MG, Dunn WL. The histochemical demonstration of o-acylated sialic acid in gastrointestinal mucins: their association with the potassium hydroxideperiodic acid-Schiff effect. $J$ Histochem Cytochem 1974;22:826-31.

${ }^{10}$ Mowry RW. Alcian-blue techniques for the histochemical study of acidic carbohydrate. J Histochem Cytochem 1956;4:407.

"Spicer SS. Diamine methods for differentiating mucosubstances histochemically. J Histochem Cytochem 1965;13:211-34.

12 Oppenheimer EH, Esterly JR. Pathology of cystic fibrosis. Review of the literature and comparison with 146 autopsied cases. Perspect Pediatr Pathol 1975;2:241-78.

${ }^{13}$ Rasor R, Stevenson C. Cystic fibrosis of the pancreas: A case history. Rocky Mountain Med.J 1941;38:218-220. Quoted by Matseshe JW, Go VLW, Di Magno EP, Gastroenterology 1977;72:732-6.

14 Jensen KG. MEconium ileus equivalent in a 15-year-old patient with mucovisidosis. Acta Paediatrica 1962;51:344-8.

is Snyder WH, Gwinn JL, Landing BH, Asay LD. Fecal retention in children with cystic fibrosis. Report of three cases. Paediatrics 1964;34:72-7.
${ }^{16}$ Mullins F, Talamo R, Di Sant' Agnese PA. Late intestinal complications of cystic fibrosis. JAMA 1965;192:741-6.

${ }^{17}$ Matseshe JW, Go VLM, Di Magno EP. Meconium ileus equivalent complicating cystic fibrosis in post natal children and young adults. Gastroenterology 1977;72:732-6.

${ }^{18}$ Hallberg D. Mucoviscidosis ileus. Acta Chirurg Scand 1964;128:201-9.

19 Brown PM, Wilson ND. Tumour of the cecum with cystic fibrosis of the pancreas. Am J Surg 1961;101:236-8.

${ }^{20}$ Blanc WA, Reid JD, Andersen DM. Avitaminosis E in cystic fibrosis of the pancreas. A morphological study of gastrointestinal and striated muscle. Pediatrics 1958;22:494-505.

${ }^{21}$ Berk RN, Lee FA. The late gastrointestinal manifestations of cystic fibrosis of the pancreas. Radiology 1973;106:377-81.

22 Parkins RA, Eidelman S, Rubin CE, Dobbins WO, Phelps PC. The diagnosis of cystic fibrosis by rectal suction biopsy. Lancet 1963 ;ii:851-6.

${ }^{23}$ Bodian M. Fibrocystic disease of the pancreas. A congenital disorder of mucous production - mucosis. London: William Heinemann Ltd, 1952.

${ }^{24}$ Shwachman H, Holsclaw D. Examination of the appendix at laparotomy as a diagnostic clue in cystic fibrosis. $N$ Eng $J$ Med 1977;286:1300-1.

${ }^{25}$ Hage E, Andersen FU. Light and electron microscopical studies of rectal biopsies in cystic fibrosis. Acta Pathol Microbiol Scand $[A]$ 1972;80:345-50.

${ }^{26}$ Oppenheimer EH, Esterly JR. Cystic fibrosis of the pancreas. Morphologic findings in infants with and without diagnostic pancreatic lesions. Arch Pathol 1973;96:149-54.

${ }^{27}$ Wesley AW, Qureshi AR, Forstner GG, Forstner JF. Differences in mucus glycoproteins of small intestine from subjects with and without cystic fibrosis. In: Chantler EN, Elder JB, Elstein M, eds. Mucus in health and disease - II New York and London: Plenum Press, 1982:145-6.

${ }^{28}$ Sheahan DG, Jervis HR. Comparative histochemistry of gastrointestinal mucosubstances. Am J Anat 1976;146:103-32.

${ }^{29}$ Culling CFA, Reid PE, Dunn WL. The effect of saponification upon certain histochemical reactions of the epithelial mucins of the GI tract. J Histochem Cytochem 1971;19:654-62.

${ }^{30}$ Morrissey SM, Tymvios MC. Acid mucins in human intestinal goblet cells. J Pathol 1978;126:197-208.

Requests for reprints to: Dr I Jeffrey, Department of Pathology, Stopford Building, The University, Manchester M13 9PT, England. 